\title{
A micro review of a nutritional public health challenge: Iron deficiency anemia in India
}

\author{
Prachiti Natekar ${ }^{\mathrm{a}}$, Chinmay Deshmukh ${ }^{\mathrm{b}, *}$, Dnyanesh Limaye ${ }^{\mathrm{c}}$, Vanisree Ramanathan ${ }^{\mathrm{a}}$, \\ Anil Pawar ${ }^{\mathrm{b}}$ \\ ${ }^{\text {a }}$ School of Public Health, Dr. Vishwanath Karad MIT World Peace University, Pune, 411038, India \\ ${ }^{\mathrm{b}}$ School of Pharmacy, Dr. Vishwanath Karad MIT World Peace University, Pune, 411038, India \\ ${ }^{c}$ School of Pharmacy and School of Public Health, Dr. Vishwanath Karad MIT World Peace University, Pune, 411038, India
}

\section{A R T I C L E I N F O}

\section{Keywords:}

Anemia

Health burden

Iron deficiency

Malnutrition

Public health

Weekly iron and folic acid supplementation

(WIFS) programme

\begin{abstract}
A B S T R A C T
Background: When a person's haemoglobin levels fall below acceptable levels, it is known as anemia, in the expressions of the World Health Organization. Anemia impacts an estimated $24.8 \%$ of the world i.e., about 1.62 billion people. The global frequency of anemia was 25\% between 1993 and 2005. The prevalent cause of anemia in the world is iron deficiency. About two billion people across the world are iron deficient.

Method: It is a review-based article. The authors reviewed different existing research papers on PubMed, science direct and web of science databases. Authors also took help of government-based information and findings.

Objective: Despite growing national and international attention, as well as current government prevention strategies, the occurrence of anemia in Indians, particularly women, has remained at 45\% since 1990, and is significantly connected to deficiency of iron. Thus, being a growing threat. As a result, it is becoming an increasing menace.

Findings: A persistently high level of anemia among Indian women that is about 53\% of all women have anemia, according to the National Family Health Survey (2015-2016) is a serious concern, and the 2017 National Health Policy recognizes such a high burden which is proposed by the Ministry of Health and Family Welfare, Government of India.

Conclusion: Although there are still significant technological hurdles in the detection of anemia in the general population, identifying its occurrence and severity is crucial. Many nations have long-standing programs aimed at preventing and controlling iron deficiency anemia, but only a handful have a well-coordinated plan to address the disease. The country's present health data infrastructure should be combined with a constant monitoring and assessment methodology so that it becomes second nature.
\end{abstract}

\section{Background}

It's all about looking good in the twenty-first century. Body shaming, bullying, and other psychological issues have become more prevalent in recent years. People have prioritized outer appearance over inner wellbeing. People prioritize their aesthetics despite knowing that everything relies on the food we consume, because of better nutrition, better health, and ultimately better appearance. Concerns about their weight, skin and entire body have all surfaced at the same time. On the contrary, people have forgotten the necessity of an appropriate diet owing to the hectic schedules of all ages owing to responsibilities. Nobody realizes, however, that it is how one feels rather than how an individual look that matters. As an individual's biological, psychological, and societal wellbeing increases, so does an individual's health.

\footnotetext{
Abbreviations: AMB, Anemia Mukt Bharat; BCC, Behavior Change Communication; GBD, Global Burden of Disease; Hb, Hemoglobin; IEC, Information, Education



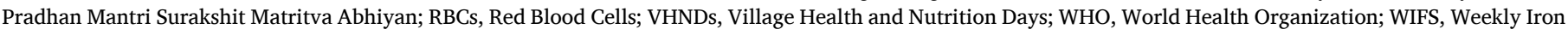
and Folic Acid Supplementation.

* Corresponding author. School of Pharmacy, Dr. Vishwanath Karad MIT World Peace University, S. No.124, MIT Campus, Paud Road, Kothrud, Pune, Maharashtra 411038, India.

E-mail addresses: prachiti.natekar@gmail.com (P. Natekar), chinmay.deshmukh@mitwpu.edu.in (C. Deshmukh), dnyanesh.limaye@mitwpu.edu.in (D. Limaye), vanisree.ramanathan@mitwpu.edu.in (V. Ramanathan), anil.pawar@mitwpu.edu.in (A. Pawar).
} 
"A state of comprehensive physical, psychological, and social wellness, rather than just the absence of illness or suffering," as per the WHO. ${ }^{1}$ we need to have the proper nutrition, exercise, and other factors for good health and wellbeing. As per WHO, nutrition is an important factor in sustaining good physical health and is an important element of health and development. ${ }^{2}$ Nutrition is essential for human survival, health, and development at all stages of life. From prenatal development to birth, infant, childhood, adolescence, maturity, and elderly, good nutrition is critical for survival, physical development, mental development, effectiveness and productivity, health, and well-being. Carbohydrates, lipids, fibre, minerals, protein, vitamins, and water are the seven primary categories of nutrients in nutrition, wherein Minerals are regarded a micronutrient in the context of the complete group of nutrition. ${ }^{3,4}$

Components that an individual's growth and development needs in small quantities are termed Micronutrients. ${ }^{5,6}$ Iron is a crucial element that aids in the production of red blood cells and a healthy system, and it is one of the many critical elements that our bodies require. ${ }^{7}$ It is also a necessary mineral for the proper functioning of the circulatory system. Iron is abundant in haemoglobin, a protein present in haemoglobin that carries oxygenated blood to all parts of the body. ${ }^{8}$ If an individual doesn't have sufficient iron, their blood cells won't be able to transmit oxygen, therefore one'll be weary. ${ }^{9}$ Myoglobin, a protein that distributes and retains oxygen in muscle tissue, also contains iron. Iron is essential for a child's brain development and growth, and also the production and function of numerous cells and hormones. The forms of iron present in food are heme and non-heme iron. ${ }^{10}$ Many foods naturally contain iron, and certain fortified meals include it as well. Breakfast cereals and bread with added iron. ${ }^{11}$

Anemia is a medical disorder defined by insufficient oxygen-carrying ability to satisfy physiological demands and is related to increased or reduced RBCs. Another very major reason for anemia is an iron deficiency; iron is an element of the blood protein haemoglobin. ${ }^{12}$ Other anomalies linked to anemia include vitamin B12 and vitamin A deficiency, parasite infections, chronic inflammation, and hereditary illnesses. The most susceptible are expectant women and children. ${ }^{13-15}$

The most widespread is Iron deficiency anemia micronutrient condition worldwide, compromising thousands of men, women, and child's health and socioeconomic status. ${ }^{16}$ Because iron deficiency is inextricably linked to poverty, it is extremely common in underdeveloped countries, where the condition is often intensified by a lack of proper care and treatment. ${ }^{17,18} \mathrm{~A}$ fairly long adverse iron balance results in depleted iron reserves, resulting in iron deficiency anemia. A shortage of iron causes iron deficiency anemia, which affects roughly 4-5 million individuals each year. ${ }^{19}$ It affects people of all ages, but the most vulnerable are children, pregnant or menstrual women, and those who need renal dialysis. ${ }^{20-22}$ The concept which describes a condition in which the body's iron stores are depleted and there is evidence of a decreased iron transport to tissues is "iron deficiency". ${ }^{9}$ Anemia caused by an abnormal iron metabolism is the most common micronutrient deficit in the world, influence the human health and economic well-being of countless men, women, and children. ${ }^{23}$ As per the World Health Organization, Anemia caused by an abnormal iron metabolism is significant health of community issue which demands immediate attention from governments, researchers, and healthcare practitioners. $^{24,25}$

Anemia is one of the leading causes of several health problem, particularly in rural areas in developing countries. ${ }^{26}$ In developing nations, low iron bioavailability in the diet is the leading cause of iron deficiency anemia. Reduced iron absorption can also be caused by gastroenteritis or malabsorption. ${ }^{27}$ Prolonged blood loss from the genitourinary, reproductive, or gastrointestinal tract is the most common cause of iron deficiency anemia. ${ }^{28,29}$ Both menstruating and expectant mothers require a lot of iron. Lactoferrin, a kind of postpartum iron, is lost in breast milk, but this is compensated by the breastfeeding woman's absence of menstruation. ${ }^{30,31}$ During pregnancy and the neonatal period, both the mother and the child suffer from postpartum iron deficiency anemia. ${ }^{25}$ In several tropical areas of the world, malaria correlates to, Anemia caused by an abnormal iron metabolism by producing vascular hemolysis and subsequent loss of erythrocyte iron in the urine. $^{15}$

\section{Method}

It is a narrative review. The review was conducted from November 2020 to June 2021. The authors accessed data from various Online published articles from official data and scientific literature using PubMed, web of science database on iron deficiency anaemia. Other reliable sources considered are the World Health Organization and the Government of India official websites, as well as individual articles from the National Health Mission initiatives.

\section{Objectives}

Iron deficiency anaemia has been the main cause of health burden in India for the past decade, based on a review of previous Global Burden of Disease (GBD) surveys. Poverty, caste issues, and poor sanitation are the principal reason for anemia in India. As per the Global Nutrition Assessment 2016, India is among the countries with the highest rates of iron deficiency, placing 170th out of 180 for women's anemia. ${ }^{27}$ Anemia caused by an abnormal iron metabolism is connected with poverty and malnutrition. The government of India has set out Rs 36,707 crore towards nutritional programs including National Health Mission's Integrated Child Development Scheme. This might be $\$ 700$ million less than the estimated needs, according to a nutrition evaluation. Other dietary programs, like the welfare schemes and the Mahatma Gandhi Rural Employment Guarantee Act, receive about Rs 2.07 lakh crore from the government, however, the system has serious flaws. ${ }^{32}$ According to a report published in January 2016, over half of the food given never reached its intended recipients. ${ }^{1}$

Another program to combat this situation is the 'NATIONAL NUTRITION ANEMIA PROPHYLAXIS PROGRAMME.' The purpose of the initiative, which started in 1970, was to avoid nutritional anemia in mothers and children. Expectant and nursing mothers, as well as birth control users, are given one iron and folacin capsule containing $60 \mathrm{mg}$ elementary iron, which has also been doubled to $100 \mathrm{mg}$ elementary iron, but the folacin dose has not changed. This program is overseen by the Ministry of Health and Family Welfare's Maternal and Child Health Division. It's now part of the Reproductive and Child Health initiative. ${ }^{11}$ The program follows few actions to have a change. The following are the actions done to combat anemia as part of the National Health Mission:

In 2018, Anaemia Mukt Bharat (AMB) was launched as part of the Strengthened Nationwide Iron Plus Initiative Project, to lower anemia rates by one to three percentage points each year. Children aged six to fifty-nine months, five to nine years, teenagers aged than to nineteen years, reproductive age group women (15-49 years), expecting women, and breastfeeding women are the target demographics for AMB (Fig. 1.) ) $33,34^{2}$

The Weekly Iron and Folic Acid Supplementation (WIFS) Program is conducted to address problems of teenage girls and boys having a great Owing to the rising prevalence of anemia. ${ }^{35}$ The WIFS approach entails 52 weeks of weekly iron-folic acid (IFA) tablet distribution under supervision (a single IFA tablet consists of $100 \mathrm{mg}$ elemental iron and $500 \mathrm{~g}$ folic acid).

- A health information system and a mother-infant surveillance system are being implemented to identify and track cases of anaemic and extremely anaemic pregnant women.

- All expecting women are given oral iron pills during their postnatal visits to the sub-centres, health facilities such as primary health centres, and also by awareness campaigns at healthcare in rural areas 


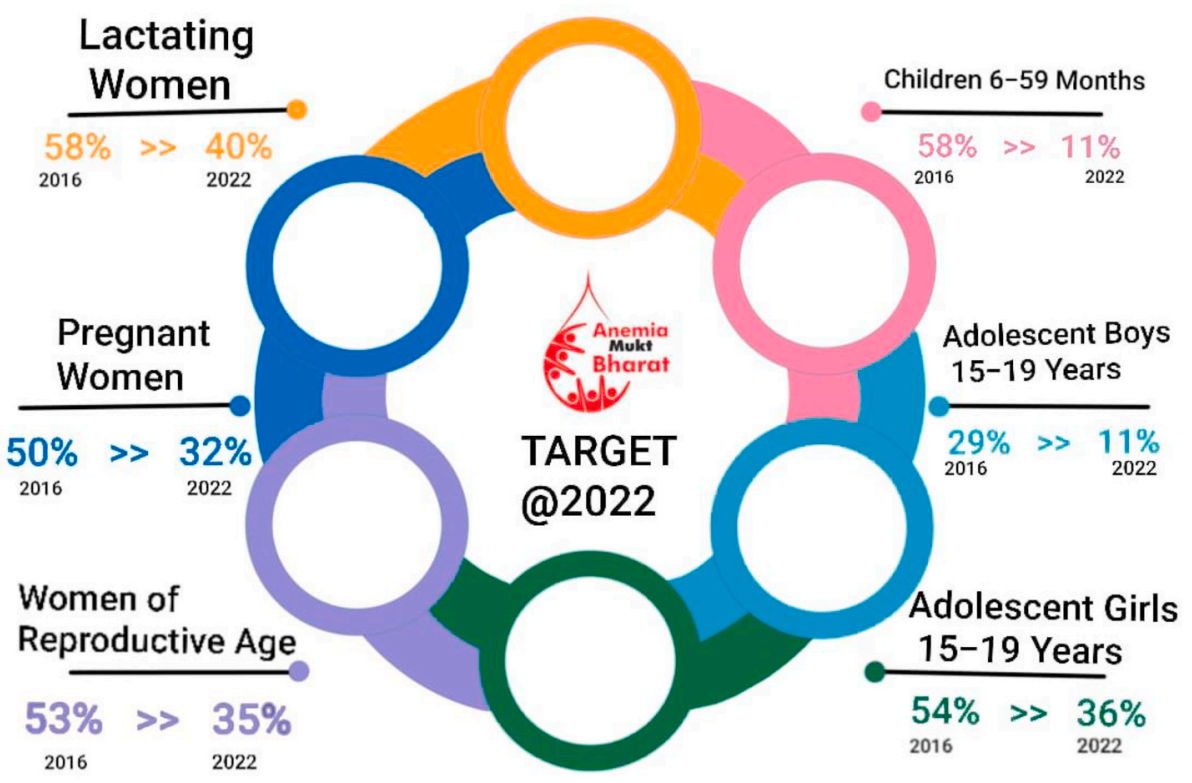

Fig. 1. Targets of Anemia Mukt Bharat 2022.

\& Village Health and Nutrition Days (VHNDs). These women are also provided dietary guidance.

- The Pradhan Mantri Surakshit Matritva Abhiyan (PMSMA) was made to conduct a special ANC examination every month's 9th day to detect and treat cases of anemia with the help of medical officers.

- To treat anemia induced by worm infection, pregnant women are dewormed after every 3 months for about 6 months.

- Steps are being taken to operationalize blood banks at district hospitals and blood storage units at sub-district facilities such as Community Hospitals/Community Health Centres to overcome the challenges presented by severe anemia.

- In endemic areas, long-lasting insecticide nets (LLINs) and insecticide-treated bed nets (ITBNs) are also being supplied to address malaria-related anemia, which impacts pregnant women and children in particular.

- Nutrition and health education are promoted through IEC and BCC to stimulate dietary diversity, the intake of iron-folate-rich foods, and the intake of foods that enhance absorption of iron (Fig. 2) ${ }^{36}$

The Ministry of Health and Family Welfare created the Weekly Iron and Folic Acid Supplementation (WIFS) Program to address the high risk of transmission of anemia in teenage males and females. WIFS is a research-based program that incorporates supervised weekly IFA dosage

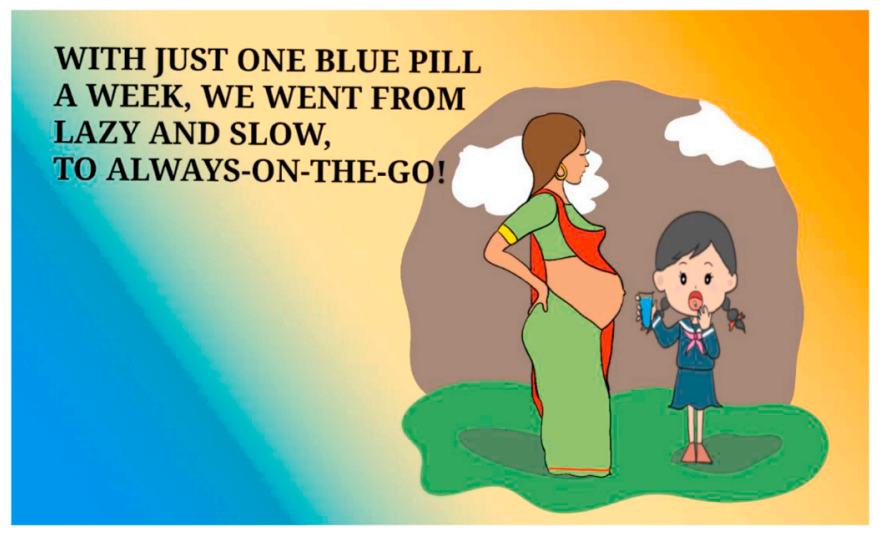

Fig. 2. Promotional poster for Weekly Iron and Folic Acid Supplementation (WIFS) Programme and weekly blood testing to address the existing anemia problem among teenage girls and boys. ${ }^{21}$

WIFS identifies itself by the following features:

WIFS (Weekly Iron Folic Acid Supplementation) is a program designed to decrease the frequency and intensity of anemia in adolescents (10-19 years).

Groups to be targeted: Adolescent girls and boys in grades six to twelve participate in government/government-aided/municipal schools.

Involvement: a predetermined day under observation is given for Weekly iron-folic acid supplements in which about $100 \mathrm{mg}$ elemental iron and $500 \mathrm{mg}$ folic acid are given. Monitoring target people with mild anemia and directing them to a suitable medical facility. Suggestions for alternating dietary intake as well as preventing intestinal worm infection.

Incorporation: The WIFS program's implementation strategy involves collaboration with stakeholder group's ministries such as the Ministry of Women and Child Development and the Ministry of Human Resource Development. A few of the important convergence areas are joint project planning, community development of key service providers such as Medical Officers, Anganwadi Workers, Staff Nurses, and School Teachers, monitoring, and a collection of best practices.

Present Situation: All states and territories have joined the project. 11.2 million individuals benefited from the initiative, including 8.4 million students and 2.8 million individuals who are not in school. ${ }^{24,37,38}$

\section{Findings}

Anemia affects around 1.62 billion people worldwide, accounting for a quarter of the world's population (24.8\%). ${ }^{39}$ According to WHO estimates from 2011, more than $40 \%$ of pregnant women globally are anaemic, which is linked to higher perinatal hazards for both mothers and babies. ${ }^{40}$ When considering the WHO-recommended Hb range of $120 \mathrm{~g} / \mathrm{L}$, the prevalence of anemia rises to $80-90 \%$. $^{22}$

Early child marriage has decreased in the fifth National Family Health Survey (NFHS), with just $21 \%$ of questioned women experiencing under-age marriages, down from $26.3 \%$ in $2015-16$. In the state of Maharashtra, the recent NHFS-5 data shows a minor decrease in adolescent pregnancy from $8.3 \%$ to $7.6 \%$ between $2015-16$ and 2019-20. Though most health statistics have recovered in the last four years, anemia rates for both women and children have deteriorated. 
Based on the latest National Family Health Survey, anemia among women and children has become worse in most states/union territories during the last half-decade (NFHS). In 2019, Anemia was found in $68.4 \%$ of youngsters and $66.4 \%$ of all women, compared to $35.7 \%$ of kids and $46.1 \%$ of the women in $2016 .{ }^{23}$ For example, children's statistics has climbed by $32.7 \%$, while women's incidence grew by $20.3 \%$ points in Assam. The Union Ministry of Health and Family Welfare conducted the very first part in NFHS-5 (2019-20) and found these results. In Jammu and Kashmir, the majority of females suffering from anemia grew by $18 \%$. In $2014,19.3 \%$ of women in Nagaland were confirmed for being anaemic, rising to $46.4 \%$ in the year 2019 . Many of the other states, including Tripura at $12.9 \%$, Mizoram at $10.1 \%$ points, and West Bengal at $10.1 \%$ points, had an upsurge in Anemia caused by an abnormal iron metabolism in women aged $15-49$ years $8.9 \%$.

The states that had a slight decline were union territories like Andaman and Nicobar Island, Dadra and Nagar Haveli, and Daman \& Diu, as well as Meghalaya, Himachal Pradesh, and Andhra Pradesh. Percent of females suffering from anemia in Meghalaya has dropped somewhat. According to the survey data, the health of women and children in Meghalaya, Andhra Pradesh, and Himachal Pradesh improved slightly. As per the NFHS-4, Haryana had the greatest percentage of students suffering from anemia (71\%), Jharkhand at $69.9 \%$, Madhya Pradesh at 68.9\%, Bihar at 63.5\%, and Uttar Pradesh at 63.5\% are the top three states. And in Union territory of Dadra and Nagar Haveli, $84.6 \%$ of children were anemic, $73.8 \%$ in the union territory of Daman and Diu, and $73.1 \%$ in the state of Chandigarh.

Jharkhand at $65.2 \%$, Haryana at $62.7 \%$, West Bengal at $62.5 \%$, Bihar at $60.3 \%$, and Andhra Pradesh at $60.3 \%$ are among states with a high proportion of women having anemia in 2016, as were that of Dadra \& Nagar Haveli at $79.5 \%$ and the state of Chandigarh at $75.9 \%$ well as the islands of Andaman and Nicobar at $65.7 \%$. For 2016, states in the northeast, such as the state of Mizoram, Manipur, Nagaland, and Sikkim, had the least numbers of anemia in both women \& children. . $^{18,41}$,

Based on the 2016 World Nutrition Assessment, India has the highest incidence of iron deficiency anemia, ranking 170th out of 180 nations of women with anemia. Malnourishment and poverty are both linked to iron deficiency anemia. The government has set out Rs 36,707 crore for nutrition-related programs such as the Integrated Child Development Scheme of the National Health Mission. According to a nutrition assessment, maybe this is 70 crores less than the predicted needs. Other programs to boost nutrition, including the welfare schemes and those under Mahatma Gandhi Rural Employment Guarantee Act, would get an extra Rs 2.07 lakh billion from the government, but the system has massive flaws. Almost half of the food sent out never makes it to the people who need it. ${ }^{5,6}$ The adoption and scaling up of the IFA Supplementation programme to the most vulnerable populations - children, adolescents, pregnant and breastfeeding mothers and would be the method for IDA prevention and management. ${ }^{42}$

\section{Conclusion}

Iron deficiency is a significant nutritional deficiency that affects individuals all over the world, particularly in developing countries. Iron needs are higher for expectant mothers, new-borns, children, and teenagers who are at the potential of becoming iron deficient. Low iron bioavailability in food is the most prevalent cause of iron deficiency in developing countries. The country's present health data infrastructure should be combined with a constant monitoring and assessment methodology so that it becomes second nature. Although there are still significant technological hurdles in detecting anemia in the general population, identifying its occurrence and severity is crucial. Studies are being conducted to produce a procedure that is relatively precise, quick, and inexpensive, and that can be administered with equipment that is not easily broken and does not rely on power. Iron deficiency and anemia prevention and management among populations with varying iron needs necessitates the coordination of various therapies. Most interventions rely on people's active engagement to succeed. Because iron deficiency is widespread it is critical to inform and educate the public, particularly through social mobilization initiatives. As a public professional strategy, it should be planned with the people we are dealing with and other aspects in mind. Many nations have longstanding programs aimed at preventing and controlling iron deficiency anemia, but only a handful have a well-coordinated plan to address the disease. In many countries, the expansion of primary health care has provided a valuable chance to control iron deficiency anemia by using an approach that is direct, economical, and easy. Food fortification is incredibly successful, but it can only be done in places with the necessary industrial infrastructure. It's usually not a good idea to base any anemia management strategy just on any of those methods; it's unlikely to be effective enough on its own.

\section{Funding support}

Nil.

\section{Ethical approval}

Not applicable.

\section{Author contributions}

Prachiti Natekar collected and reviewed the data. All authors read, formatted and approved the final manuscript.

\section{Declaration of competing interest}

Authors declare that they have no competing interests.

\section{References}

1 Rai R, Fawzi W, Barik A, Chowdhury A. The burden of iron-deficiency anaemia among women in India: how have iron and folic acid interventions fared? WHO South-East Asia. Internet J Publ Health. 2018;7(1):18. Available from http://www.wh o-seajph.org/article.asp?issn $=2224-3151$; year $=2018$; volume $=7$; issue $=1$; spage $=18$; epage $=23$; aulast $=$ Rai\# $\#$ ref14.

2 Narayan J, John D, Ramadas N. Malnutrition in India: status and government initiatives. Internet $J$ Publ Health Pol. 2019;40(1):126-141. Available from https ://www ncbi.nlm.nih.gov/pubmed/30353132.

3 World Health Organization. Malnutrition Internet. Who.Int. World Health Organization: WHO; 2021. Available from https://www.who.int/news-room/fact-sheets/detail/ malnutrition.

4 Kramer M. Nutrition and Child Development in Low- and Middle-Income Countries Evaluation of Three Micronutrient Interventions Internet; 2017. Available from htt ps://d-nb.info/1136785191/34.

5 Yadavar S. Anaemia Is the Biggest Cause of Disability in India, Worst in BRICS. Business Standard India Internet; 2016 Oct 27. Available from https://www.business-standard. com/article/economy-policy/anaemia-is-the-biggest-cause-of-disability-in-indiaworst-in-brics-116102700695_1.html.

6 Kumar P. Anaemia Rising Among Women and Children in NE | Outlook Poshan Internet. Available from https://poshan.outlookindia.com/. 2021. https://poshan. outlookindia.com/story/poshan-news-anaemia-rising-among-women-and-chi ldren-in-ne/372999.

7 Oleribe OO, Ukwedeh O, Burstow NJ, et al. Health: redefined. Internet Pan African Medical Journal. 2018 Aug 24;30, 30:292 https://www.panafrican-med-journal.com/ content/article/30/292/full/. Available from.

8 Lal A. Iron in health and Disease: an update. Indian J Pediatr. 2019 Sep 13;87(1): 58-65.

9 Abbaspour N, Hurrell R, Kelishadi R. Review on iron and its importance for human health. $J$ Res Med Sci: the official journal of Isfahan University of Medical Sciences Internet. 2013 Nov 27;19(2):164-174. Available from https://www.ncbi.nlm.nih. gov/pmc/articles/PMC3999603/.

10 Iron Internet. The Nutrition Source. Harvard Chan School of public health; 2019. Available from https://www.hsph.harvard.edu/nutritionsource/iron/.

11 National Institute of Health and Family Welfare (NIHFW). National institute of health \& family welfare internet. Nihfw.org.; 2019. Available from: http://www. nihfw.org/.

12 Weekly iron folic acid supplementation (WIFS): national health mission internet. Nhm.gov.in. Available from https://www.nhm.gov.in/index1.php?lang=1\&leve $l=3 \&$ sublinkid $=1024 \&$ lid $=388$.

13 World Health Organization Nutrition for Health and Development (NHD). Sustainable development and healthy environments (SDE) for health and development internet. World Health Organization. World Health Organization. 
Available from: http://apps.who.int/iris/bitstream/handle/10665/665 09/WHO_NHD_00.6.pdf.

14 Ndn B. Iron deficiency anemia | nutrition guide for clinicians internet. Pcrm.org. Nutrition guide for clinicians. Physicians Committee for Responsible Medicine; 2016 Available from https://nutritionguide.pcrm.org/nutritionguide/view/Nutrition Guide_for_Clinicians/1342090/all/Iron_Deficiency_Anemia.

15 Jimenez K, Kulnigg-Dabsch S, Gasche C. Management of iron deficiency anemia. Internet Gastroenterol Hepatol. 2015 Apr;11(4). Available from: https://www.ncbi. nlm.nih.gov/pmc/articles/PMC4836595/pdf/GH-11-241.pdf.

16 Baltussen R, KnaiC Sharan M. Iron fortification and iron supplementation are costeffective interventions to reduce iron deficiency in four subregions of the world. Internet $J$ Nutr. 2004 Oct 1;134(10):2678-2684. Available from: https://academic. oup.com/jn/article/134/10/2678/4688367.

17 National Institutes of Health. Office of Dietary Supplements - Iron Internet. Nih.Gov; 2016. Available from https://ods.od.nih.gov/factsheets/Iron-Consumer/.

18 Sharma A. Eliminating Female Anaemia in India: Prevalence, Challenges and Way Forward Internet; 2021 Apr:335. Available from https://sprf.in/wp-content/uploads/ 2021/04/SPRF-2021_IB_Anaemia-among-Indian-Women_Final.pdf.

19 Bathla S, Arora S. Prevalence and approaches to manage iron deficiency anemia (IDA). Critical Reviews in. Food Sci Nutr. 2021 Jun 7;(1-14):1-14.

20 Abu-Ouf N, Jan M. The impact of maternal iron deficiency and iron deficiency anemia on child's health. Internet Saudi Med J. 2015 Feb 26;36(2):146-149. Available from: https://www.ncbi.nlm.nih.gov/pmc/articles/PMC4375689/.

21 Aggarwal A, Aggarwal A, Goyal S, Aggarwal S. Iron-deficiency anemia among adolescents: a global public health concern. International Journal of Advanced Community Medicine. 2020 Apr 1;3(2):35-40.

22 DeMaeyer EM, Dallman P, Gurney JM, Sood SK. Preventing and controlling iron deficiency anemia through primary healthcare. Available from: https://www.who. int/nutrition/publications/micronutrients/anaemia_iron_deficiency/9241542497. pdf.

23 Rocha ÉMB, Lopes AF, Pereira SM, et al. Iron deficiency anemia and its relationship with socioeconomic vulnerability. Internet Revista Paulista de Pediatria; 2020:38. Available from https://www.ncbi.nlm.nih.gov/pmc/articles/PMC7274531/.

24 Nieder R, Benbi D, Reichl F. Micronutrient availability, chemistry and availability of micronutrients in soils. J Agric Food Chem. 1962 May;10(3):174-178.

25 Malinowski A, D’Souza R, Khan Khalid S, Shehata N, Malinowski M, Daru J. Reported outcomes in perinatal iron deficiency anemia trials: a systematic review. Internet Gynecol Obstet Invest. 2019;84(5):417-434. Available from: https://pubmed. ncbi.nlm.nih.gov/30712041/.

26 Sheth PA, Pawar AT, Mote CS, More C. Antianemic activity of polyherbal formulation, Raktavardhak Kadha, against phenylhydrazine-induced anemia in rats. J Ayurveda Integr Med. 2021;12(2):340-345. https://doi.org/10.1016/j. jaim.2021.02.009.

27 Kapur D, Agarwal KN, Agarwal DK. Nutritional anemia and its control. Internet Indian J Pediatr. 2002 Jul 1;69(7):607-616. Available from https://pubmed.ncbi.nlm .nih.gov/12173702/.
28 Cappellini MD, Musallam KM, Taher AT. Iron deficiency anemia revisited. J Intern Med. 2019 Oct 30;(2):287.

29 Johnson-Wimbley TD, Graham DY. Diagnosis and management of iron deficiency anemia in the 21st century. Internet Therapeutic Advances in Gastroenterology. 201 Mar 21;4(3):177-184. Available from: https://www.ncbi.nlm.nih.gov/pmc/artic les/PMC3105608/.

30 Shidhaye P, Nagaonkar S, Giri P, Shidhaye R. Prevalence of anemia in the postnatal women at a tertiary care teaching hospital in Mumbai. J Med Nutr Nutraceuticals. 2012;1(1):54.

31 Miller JL. Iron deficiency anemia: a common and curable Disease. Internet Cold Spring Harbor Perspectives in Medicine. 2013 Apr 23;3(7). a011866-6 https://www.nc bi.nlm.nih.gov/pmc/articles/PMC3685880/. Available from.

32 Shubham K, Anukiruthika T, Dutta S, Kashyap AV, Moses JA, Anandharamakrishnan C. Iron deficiency anemia: a comprehensive review on iron absorption, bioavailability and emerging food fortification approaches. Internet Trends Food Sci Technol. 2020 May;99:58-75. Available from https://www.sciencedir ect.com/science/article/abs/pii/S0924224419307290.

33 Anemia Mukt Bharat | A programme by Ministry of Health and UNICEF Internet. Anemia Mukt Bharat dashboard. Available from https://anemiamuktbharat.info/.

34 Bhatia PV, Sahoo DP, Parida SP. (PDF) India Steps Ahead to Curb Anemia: Anemia Mukt Bharat Internet. ResearchGate. Indian Journal of Community Health; 2018. Available from https://www.researchgate.net/publication/331877720 India st eps_ahead to curb anemia_Anemia_Mukt Bharat.

35 Christofides A, Schauer C, Zlotkin SH. Iron deficiency anemia among children: addressing a global public health problem within a Canadian context. Internet Paediatr Child Health. 2005 Dec 1;10(10):597-601. Available from https://www.nc bi.nlm.nih.gov/pmc/articles/PMC2722615/.

36 Choubey AK. Anaemia in Women Internet. Pib.Gov. Ministry of Health and Family Welfare; 2019. Available from https://pib.gov.in/PressReleasePage.aspx? PRID $=1575151$.

37 Dhikale P, Suguna E, Thamizharasi A, Dongre A. Evaluation of weekly iron and folic acid supplementation program for adolescents in rural pondicherry, India. Int J Med Sci Publ Health. 2015;4(10):1360.

38 Yip R. Prevention and control of iron deficiency: policy and strategy issues. J Nutr. 2002 Apr 1;132(4), 802S805S.

39 García López S, Rubio A, Poza V, Bermejo García López S. Optimal management of iron deficiency anemia due to poor dietary intake. Internet Int J Gen Med. 2011 Oct;4: 741-750. Available from: https://pubmed.ncbi.nlm.nih.gov/22114518/.

40 Anand T, Rahi M, Sharma P, Ingle GK. Issues in prevention of iron deficiency anemia in India. Internet Nutrition. 2014 Jul;30(7-8), 764-70 https://pubmed.ncbi.nlm.nih. gov/24984990/. Available from.

41 Challa S. Surveillance of anaemia: mapping and grading the high-risk territories and populations. J Clin Diagn Res. 2016;10.

42 Guidelines for Control of Iron Deficiency Anaemia; 2013. Internet . Accessed July 10, 2021. 